\title{
LET'S SPEAK UP : PELATIHAN PUBLIC SPEAKING “PEMUDA PEMBENTUK PERADABAN DI ERA MILLENIAL"
}

\author{
Diah Ayu Septi Fauji ${ }^{1}$, Ismayantika Dyah Puspasari \\ Fakultas Ekonomi,Universitas Nusantara PGRI Kediri \\ ${ }^{1}$ Korespodensi : septifauji@unpkediri.ac.id
}

\begin{abstract}
The development of Indonesia in the future depends on the role of the youth. But now many young people are still embarrassed to speak in public (public speaking), therefore it takes practice on public speaking. The theme of this training is "Youth Forming Civilization in the Millennial Era which aims to train the ability to speak in public by speaking according to the theme. The first training phase: the initial survey of youth constraints in public speaking, the second is material training and the practice of public speaking, the third stage is the accompaniment of the practice of public speaking and evaluation. As a result of this training the participants had the ability to speak in front of an increasing public.
\end{abstract}

Keywords: youth, public speaking, training speaking

\begin{abstract}
ABSTRAK
Perkembangan Indonesia di mendatang tergantung dari peran pemudanya. Namun saat ini banyak pemuda yang masih malu untuk berbicara di depan umum (public speaking), oleh karenanya dibutuhkan latihan tentang public speaking. Dalam pelatihan ini diambil tema "Pemuda Pembentuk Peradaban di Era Millenial yang bertujuan untuk melatih kemampuan berbicara didepan umum dengan berbicara sesuai tema. Adapun tahap pelatihan ini pertama : survei awal kendala- kendala pemuda dalam berbicara didepan umum, kedua adalah pelatihan materi dan praktik public speaking, tahap ketiga yaitu pendampingan praktik public speaking dan evaluasi. Hasil dari pelatihan ini peserta memiliki kemampuan berbicara didepan publik yang meningkat.
\end{abstract}

Kata kunci: pemuda, public speaking, training speaking

\section{PENDAHULUAN}

Sebagai makhluk sosial tentunya sangat perlu menyampaikan pesan kepada mitra bicara dengan tepat. Namun, tidak bisa dipungkiri bahwa dibutuhkan juga strategi dalam menyampaikan pesan tersebut. Sesuai yang disampaikan oleh Tarigan ( 1998:15) bahwa berbicara adalah seni, karena bicara merupakan alat menyampaikan gagasan yang disusun sesuai kebutuhan. Jadi belajar berbicara didepan umum berarti belajar seni 
memahami kondisi lawan bicara, memahami pendengar, memahami tujuan berbicara sehingga pembicara memahami bagaimana cara menyampaikan yang tepat.

Hasyim \& D.W(2014) mengatakan bahwa Public speaking adalah skill spesial dari sekedar berbicara dengan orang lain. Public speaking membutuhkan persiapan karena sifatnya lebih banyak ditujukan untuk berkomunikasi, mengajak banyak orang, mengubah opini dan memberi informasi.

Lebih lanjut dikatakan Wibawa, Sarwoko, Cahyono, \& Suciska (2012) kebanyakan orang takut berbicara didepan umum, bahkan ketakutan berbicara didepan umum lebih besar daripada ketakutan terhadap ketinggian. Jika tidak dilakukan latihan maka akan menimbulkan gejala psikologis yang hebat pada seseorang yang belum terbiasa berbicara didepan umum.

Oleh karenanya memang perlu sekali dilakukan pelatihan. Pelatihan ini khususnya merupakan tindak lanjut dari kegiatan bedah buku tahun 2018 yang mana pada saat itu peserta yang terdiri dari siswa-siswi SMA/SMK, Mahasiswa. Namun, pada acara tersebut diketahui juga bahwa ternyata masih banyak pemuda- pemudi yang malu untuk berbicara di depan umum. Malu untuk menyampaikan pendapat bahkan malu untuk memperkenalkan dirinya di depan publik.

Adanya pelatihan ini juga diharapkan menjadi sarana belajar dan juga latihan bagi para pemuda di Kediri untuk lebih siap berbicara di depan publik. Selain itu para peserta juga dapat lebih percaya diri tampil didepan umum, terampil dalam berbicara dan bisa digunakan pada saat menjadi MC dalam kegiatan RT, Karang taruna maupun acara lainnya.

\section{METODE PELAKSANAAN}

Sasaran pelatihan ini adalah bagi pemuda di wilayah kediri baik itu siswa SMP, SMA, dan juga Mahasiswa. Kegiatan - kegiatan yang dilakukan meliputi :

Tabel 1. Uraian Kegiatan

\begin{tabular}{|l|l|l|}
\hline No & Keterangan & Durasi (jam) \\
\hline 1 & Pengenalan Public Speaking & 2 \\
\hline 2 & Pelatihan teknik Public Speaking & 2 \\
\hline 3 & Pendampingan Praktik Public Speaking & 4 \\
\hline
\end{tabular}


1. Pemaparan tentang materi public speaking, faktor- faktor yang menghambat dan juga faktor yang mendukung berhasilnya seseorang berbicara didepan umum. Oleh Diah Ayu Septi Fauji, M.M.

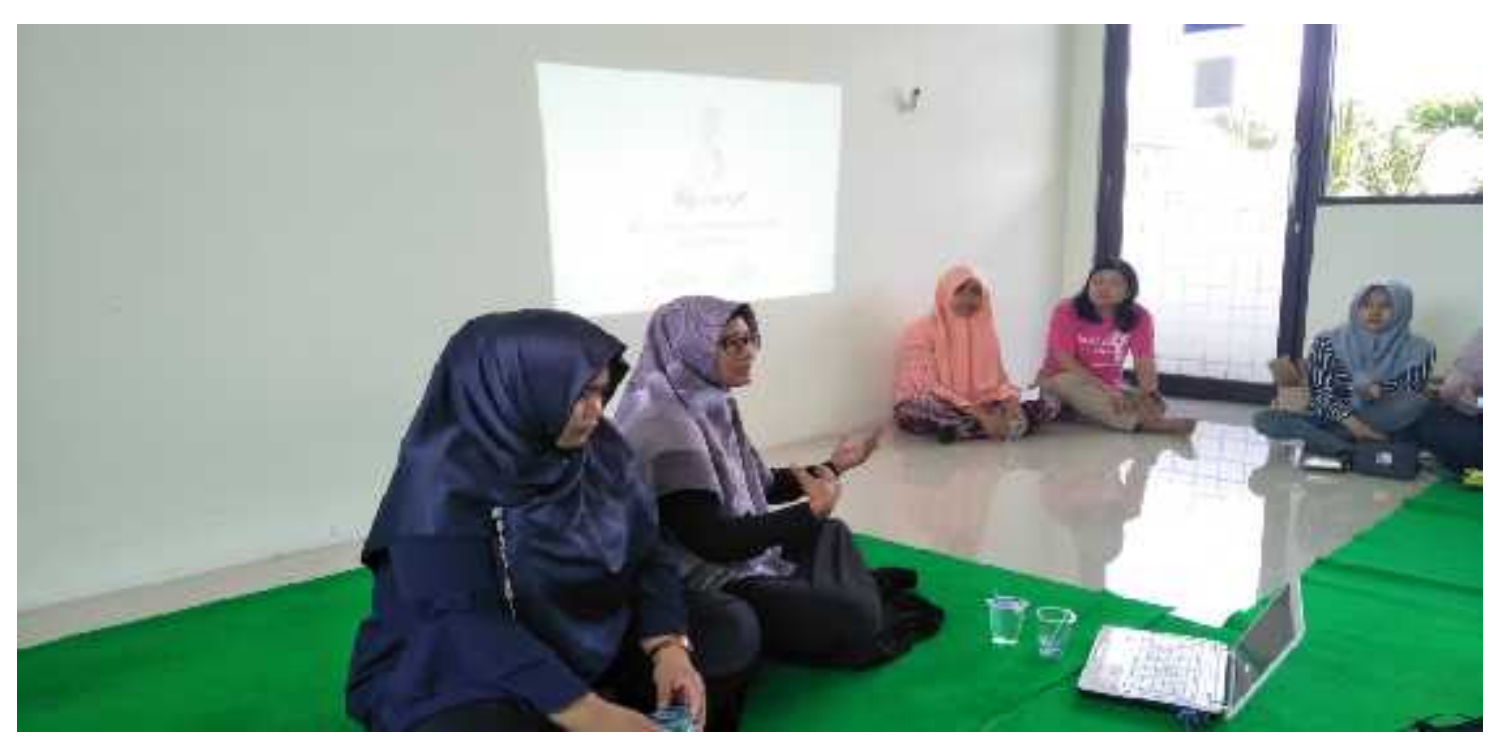

\section{Gambar 1. Pemaparan materi public speaking}

Pada tahap ini pemateri mengutip dari Sirait(2008) yang menyatakan tentang hal - hal yang harus diperhatikan untuk menjadi public speaker diantaranya adalah :

a. Sebagai pembicara harus mengungkapkan pujian dan pandangan positif kepada publik dan tokoh yang dibicarakan

b. Meneliti sebelum berbicara sehingga tidak mempermalukan diri sendiri dan orang lain dihadapan publik

c. Tulus menyampaikan pujian

d. Bercerita nostalgia sebelum menyampaikan materi

e. Berlatih berpikir dan berbicara positif

f. Berlatih kritis memeriksa kekurangan

g. Berkonsultasi dengan orang terdekat saat kita ragu atas materi yang disampaikan 
2. Pelatihan teknis berbicara di depan umum oleh Ismayantika Dyah Puspasari, M.B.A.

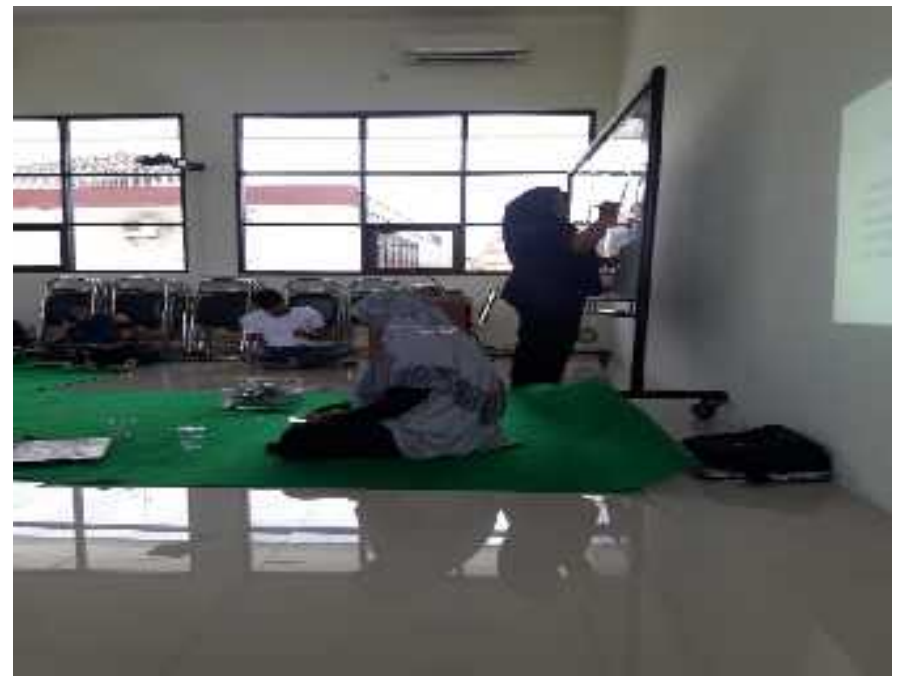

\section{Gambar 2. Pelatihan Teknik Public Speaking}

3. Pendampingan Pembuatan Video oleh aktivis peneleh regional kediri

4. Show up dan evaluasi

\section{HASIL DAN PEMBAHASAN}

Hasil dari pelatihan ini bermanfaat bagi masing - masing peserta khususnya terkait kemampuan berbicara didepan umum. Berikut beberapa gambar yang menunjukkan praktik peserta.

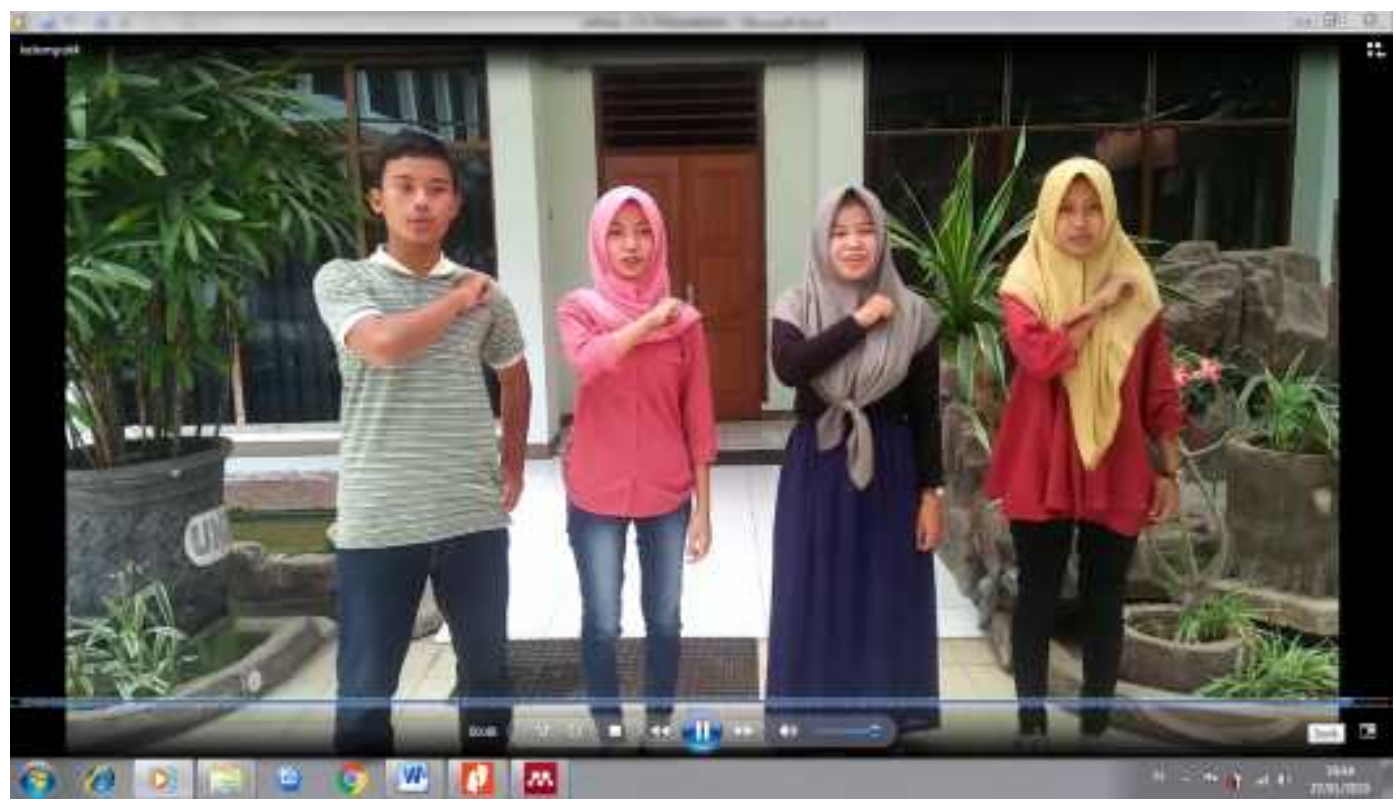


Gambar 3. Prakti peserta public Speaking kelompok 1

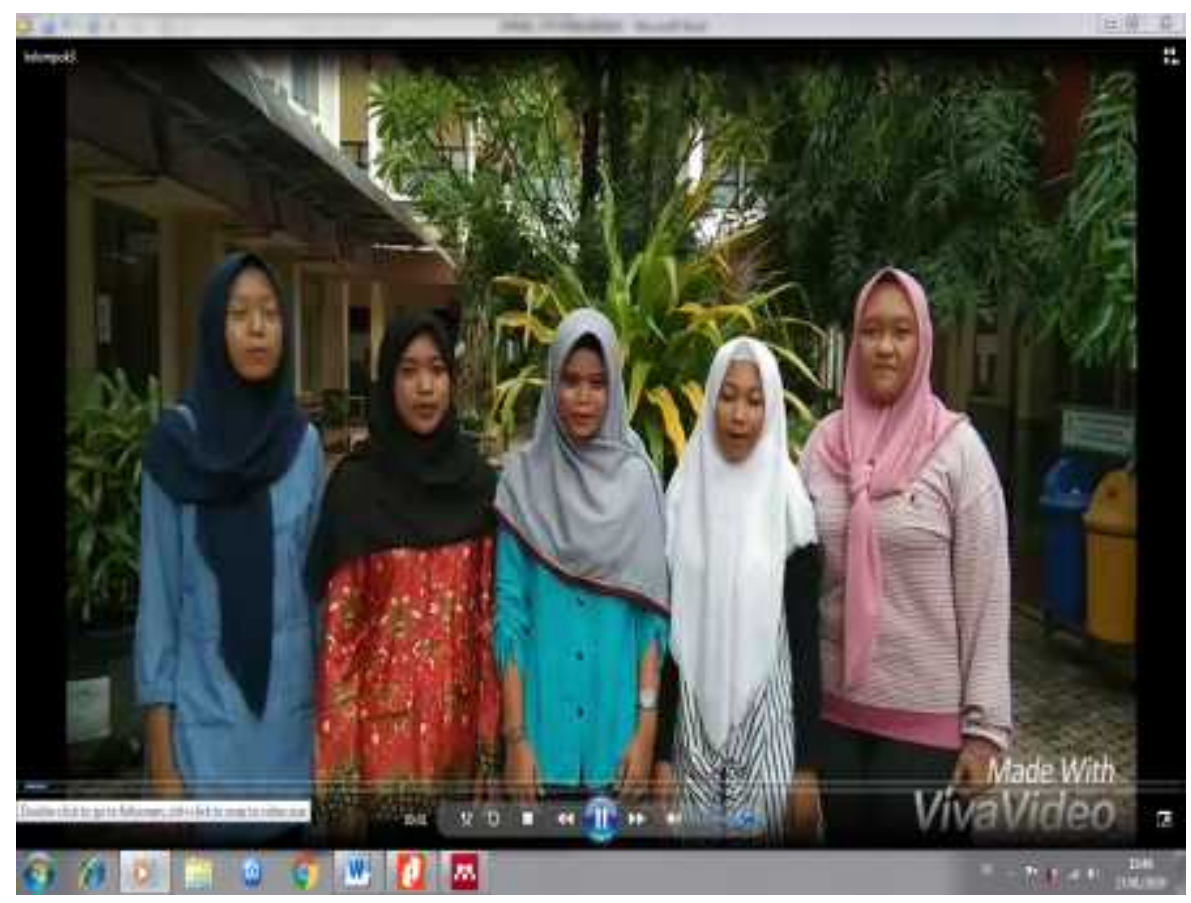

Gambar 4. Prakti peserta public Speaking kelompok 2

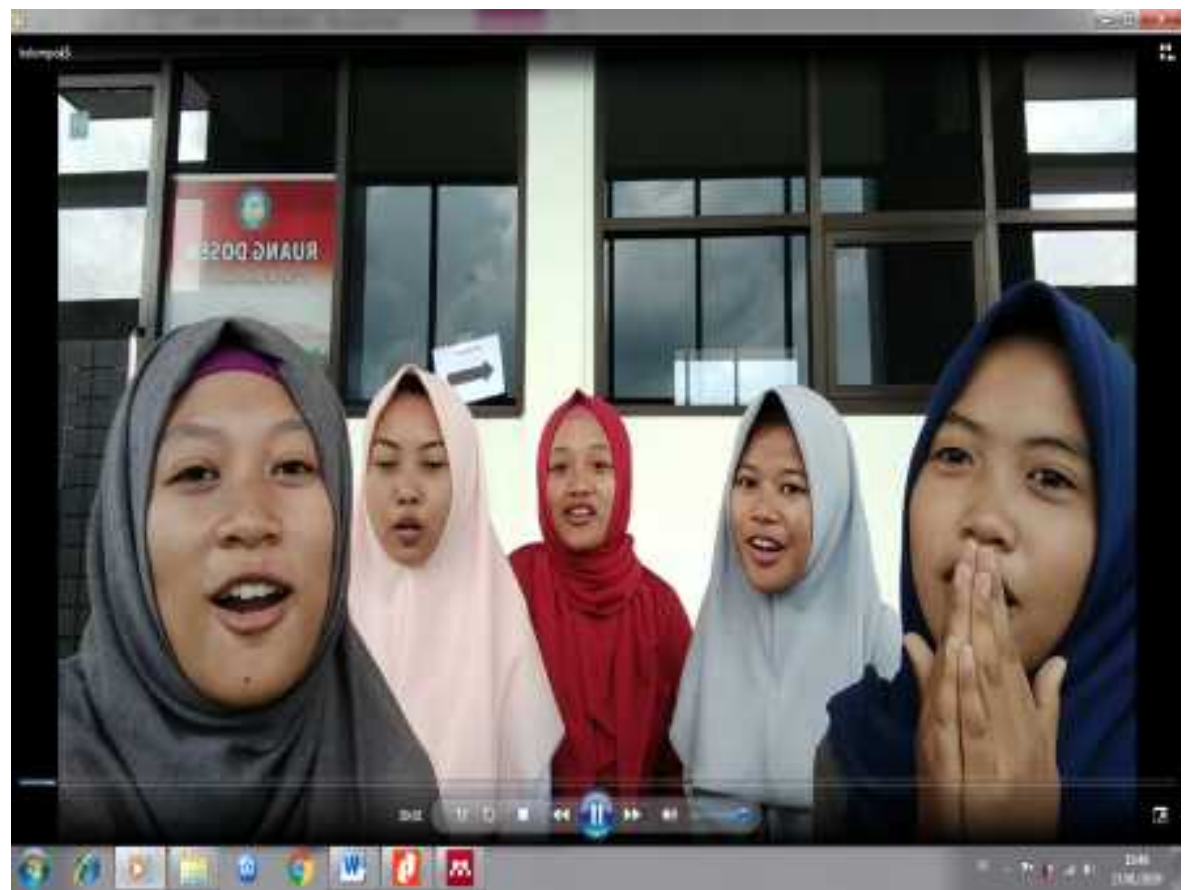

Gambar 5 Prakti peserta public Speaking kelompok 3 
Dari serangkaian acara yang telah dilaksanakan peserta memperoleh pengetahuan tentang apa itu public speaking, cara- cara berbicara didepan umum. Pemateri pertama menyampaikan tentang ketrampilan berbicara, bagaimana menjadi pembicara yang baik, apa saja yang diperlukan untuk menjadi pembicara yang baik, apa saja hambatan yang mungkin muncul saat menjadi pembicara.

Dalam hal ini pemateri juga menyampaikan contoh - contoh para pembicara yang sering muncul di TV berbicara didepan umum. Pengenalan public speaking dikondisikan untuk lebih aktif, pemateri menyampaikan materi dengan santai dan bersahabat. Pemateri juga memberi motivasi dan stimuli untuk membuat peserta bergairah dan bersemangat sehingga materi yang disampaikan selama pelatihan benarbenar bisa diterapkan peserta. Selain itu pemateri menyampaikan bahwa setiap orang memiliki modal untuk berbicara didepan publik. Setiap orang memiliki 3 L (Lahir (bakat), Lingkungan, Latihan) sebagai modal untuk berani berbicara didepan umum, tinggal apakah orang tersebut mau melakukan atau tidak.

Selanjutnya adalah penyampaian teknik public speaking, pemateri menyampaikan cara - cara berbicara didepan umum. Pemateri juga menjelaskan bahwa pemuda yang memiliki banyak kemampuan harusnya berani berbicara dengan tegas, lantang tanpa malu-malu. Karena masa depan Indonesia berada ditangan para pemuda, maka setiap pemuda harus berani keluar dari zona nyamannya dan berani turut serta menyampaikan pendapat untuk kemajuan lingkungan dan juga negaranya.

Tahapan berikutnya adalah Tahap praktik public speaking yang didampingi oleh aktivis peneleh regional kediri.pada tahap ini topik materi yang akan dibahas oleh peserta adalah tentang Pemuda Pembentuk Peradaban di Era Millenial. Peserta memilih berbagai macam alasan pemuda dapat berperan serta dalam membentuk peradaban negeri ini, dimulai dari lingkungan sekitar. Rangkaian kegiatan nya meliputi :

\section{a. Pembagian kelompok}

Kelompok dipilih secara acak, agar peserta saling mengenal teman dari luar lingkungan dekatnya. Peserta menyebutkan nomor 1- 5 berulang, jadi bagi yang menyebutkan nomor 1 maka dia akan bergabung dengan kelompok 1 dan seterusnya. Agar efektif kelompok hanya dibatasi maksimal 5 orang. Dan dalam kesempatan ini ada 5 (lima) kelompok dengan masing- masing kelompok 
beranggotakan 5 orang sebanyak 3 kelompok dan 2 kelompok beranggotakan 4 orang.

b. Penentuan bahan

Tahap ini peserta diarahkan untuk membahas isu- isu terkini disekitar mereka, dan membuat pendapat. Dalam bagian ini berisi :1) pendahuluan, 2) isi, 3) simpulan, 4) penutup dari seluruh anggota kelompok.

c. Tahap tampil percaya diri didepan kamera

Tahap ini merupakan tahap puncak dimana peserta didampingi oleh aktivis peneleh regional kediri selaku tim pengabdian pada masyarakat untuk tampil secara individu kemudian berkelompok menyampaikan pesan kepada audiens di depan kamera. Acara ini berlangsung seru, karena peserta beberapa kali mengulang materi yang disampaikan hingga benar- benar lancar.

Setelah semuanya tampil, kemudian sampai pada tahap evaluasi. Saat show - up pemateri langsung memberikan evaluasi kepada peserta untuk memperbaiki penampilan. Setelah itu, peserta menyampaikan refleksi perasaan mengikuti acara ini.

Acara ini menghasilkan peningkatan kemampuan berbicara peserta dalam berpidato, menyampaikan pendapat didepan umum dan membawakan acara. Hasil dari pelatihan ini juga menguatkan pengabdian sebelumnya yang dilakukan oleh Nugrahani \& Kustantinah,.( 2013).

\section{KESIMPULAN}

Untuk mengajak pemuda lebih aktif dan berani menyampaikan pendapat, menyampaikan materi didepan publik maka perlu sekali untuk melakukan latihan. Karena berbicara didepan umum tidak semudah yang dibayangkan sehingga memerlukan pelatihan. Acara pelatihan semacam ini terbukti dapat meningkatkan keberanian peserta untuk berbicara didepan umum, sehingga harus berkelanjutan dengan harapan peserta dapat sering berlatih dan mempraktikannya.

\section{DAFTAR PUSTAKA}

Hasyim, M., \& D.W, I. (2014). Pelatihan Public Speaking Pada Remaja Dan AnakAnak Dusun Puluhan, Desa Banyusidi , Pakis , Magelang, Jawa Tengah. Jurnal Inovasi Dan Kewirausahaan, 3(2), 96-100. 
Nugrahani, D., \& Kustantinah, I. (2013). Peningkatan Kemampuan Public Speaking Melalui Metode Pelatihan Anggota Forum Komunikasi.

Sirait, B. C. (2008). The Power of Public Speaking: Kiat Sukses Berbicara di Depan Publik. Jakarta: Gramedia Pustaka Utama.

Tarigan, H. G. (1998). Berbicara Sebagai Suatu Ketrampilan Berbahasa. Bandung.

Wibawa, A., Sarwoko, Cahyono, E., \& Suciska, W. (2012). Pelatihan Dasar Public Speaking (Pelatihan Bagi Pegawai Negeri Sipil dan Tokoh Masyarakat di Wilayah Desa Taman Bogo Kecamatan Purbalingga, Lampung Timur). In Seminar Hasilhasil Penelitian dan Pengabdian kepada Masyarakat Dies Natalies FISIP UNILA, Lampung. 